\title{
Straw application in paddy soil enhances methane production also from other carbon sources
}

\author{
Q. Yuan, J. Pump, and R. Conrad \\ Max Planck Institute for Terrestrial Microbiology, Karl-von-Frisch-Str. 10, 35043 Marburg, Germany \\ Correspondence to: Q. Yuan (quan.yuan@mpi-marburg.mpg.de)
}

Received: 24 July 2013 - Published in Biogeosciences Discuss.: 26 August 2013

Revised: 8 December 2013 - Accepted: 10 December 2013 - Published: 22 January 2014

\begin{abstract}
Flooded rice fields are an important source of the greenhouse gas methane. Methane is produced from rice straw (RS), soil organic matter (SOM), and rice root organic carbon (ROC). Addition of RS is widely used for ameliorating soil fertility. However, this practice provides additional substrate for $\mathrm{CH}_{4}$ production and results in increased $\mathrm{CH}_{4}$ emission. Here, we found that decomposing RS is not only a substrate of $\mathrm{CH}_{4}$ production, but in addition stimulates $\mathrm{CH}_{4}$ production from SOM and ROC. Apart from accelerating the creation of reduced conditions in the soil environment, RS decomposition resulted in enhancement of SOM-derived $\mathrm{CH}_{4}$ production. In particular, hydrogenotrophic methanogenesis from $\mathrm{SOM}$-derived $\mathrm{CO}_{2}$ was stimulated, presumably by $\mathrm{H}_{2}$ released from $\mathrm{RS}$ decomposition. On the other hand, the enhancement of ROC-derived $\mathrm{CH}_{4}$ production after $\mathrm{RS}$ application was probably caused by the significant increase of the abundance of methanogenic Archaea in the RS treatment compared with the untreated control. Our results show that traditional management of rice residues exerts a positive feedback on $\mathrm{CH}_{4}$ production from rice fields, thus exacerbating its effect on the global $\mathrm{CH}_{4}$ budget.
\end{abstract}

\section{Introduction}

Flooded rice fields are one of the largest sources of atmospheric $\mathrm{CH}_{4}$, the second most important greenhouse gas (Lelieveld et al., 1998). Estimates of rice fields $\mathrm{CH}_{4}$ emission range from 31 to $112 \mathrm{Tg} \mathrm{yr}^{-1}$, accounting for up to $19 \%$ of global total emissions (Forster et al., 2007). Change in $\mathrm{CH}_{4}$ cycling due to agroecosystem management has an immediate impact on climate due to the relatively short lifetime of $\mathrm{CH}_{4}$ in the atmosphere (Montzka et al., 2011). Methane and $\mathrm{CO}_{2}$ are end products of decomposition of organic matter in anoxic rice field soil (Kimura et al., 2004). The organic materials available for anaerobic decomposition are mainly derived from three sources (Chidthaisong and Watanabe, 1997; Watanabe et al., 1999): (1) soil organic matter (SOM), (2) root organic carbon (ROC) including root exudates and sloughed-off dead root, and (3) incorporated organic material such as rice straw (RS), which is often applied in large amounts (up to $12 \mathrm{tha}^{-1}$ annually) to maintain soil fertility. Knowledge of the partitioning the $\mathrm{CH}_{4}$ production among these three types of organic materials is important for improving process-based modeling of $\mathrm{CH}_{4}$ emission from rice fields, which is the basis for predicting methane flux and assessing the impact of agricultural management and global change (Fumoto et al., 2008; Li et al., 2004; Tokida et al., 2010). So far, there are only few studies that have quantified the relative contribution of each individual source to total $\mathrm{CH}_{4}$ production and emission (Tokida et al., 2011; Watanabe et al., 1999; Yuan et al., 2012). It is possible that contribution of each individual source could change greatly with the amount of RS applied (Watanabe et al., 1998).

More interestingly, the RS applied may not only serve as the substrate for $\mathrm{CH}_{4}$ production, but might also affect $\mathrm{CH}_{4}$ production from the other (SOM, ROC) carbon sources (Chidthaisong and Watanabe, 1997; Watanabe et al., 1998). It has been argued that the decomposed RS may promote $\mathrm{CH}_{4}$ production from the other carbon sources by accelerating the creation of reduced soil conditions (Tokida et al., 2010; Watanabe et al., 1998). However, there is an alternative possibility. Labile carbon addition (such as straw or cellulose) could stimulate decomposition of more recalcitrant SOM (De Troyer et al., 2011; Guenet et al., 2012) eventually resulting in stimulated $\mathrm{CH}_{4}$ production. Such stimulation of 
SOM decomposition is called a priming effect. Priming effects have frequently been reported in upland soils where $\mathrm{CO}_{2}$ is the only end product of decomposition of organic matter (Kuzyakov and Bol, 2006; Zhu and Cheng, 2011), but they have rarely been studied in rice field soils where both $\mathrm{CO}_{2}$ and $\mathrm{CH}_{4}$ are the end products of anaerobic decomposition of organic matter (Conrad et al., 2012b).

In this study, we explored the possibility of enhancing $\mathrm{CH}_{4}$ production from SOM and ROC by RS application. Moreover, we investigated whether there is a priming effect of RS on anaerobic SOM decomposition. These objectives required the quantification of the partitioning of $\mathrm{CH}_{4}$ and $\mathrm{CO}_{2}$ production from the individual carbon sources (i.e., from ROC, SOM and RS). Recently, we introduced a novel technique by treating rice microcosms with rice straw that was enriched in ${ }^{13} \mathrm{C}$ so that it was possible to differentiate between the C-flux derived from either RS or from ROC and SOM (Yuan et al., 2012). Applying this technique, we were able to detect the enhancement of $\mathrm{RS}$ on $\mathrm{CH}_{4}$ production from both ROC and SOM using rice field soil from Vercelli, Italy.

\section{Material and methods}

\subsection{Greenhouse experiment}

\subsubsection{Planted and unplanted rice microcosms}

Soil was taken from a drained paddy field of the Italian Rice Research Institute in Vercelli, Italy, in spring 2009 and was air-dried and stored at room temperature. The soil was sieved $(<2 \mathrm{~mm})$ prior to use. The characteristics of the soil have been described previously (Holzapfel-Pschorn and Seiler, 1986). Planting pots (upper diameter $=19 \mathrm{~cm}$; lower diameter $=14 \mathrm{~cm}$; height $=16 \mathrm{~cm}$ ) were filled with $2 \mathrm{~kg}$ dry soil and turned into a slurry with demineralized water.

Preparation of such microcosms has been described previously (Yuan et al., 2012). In brief, 48 pots were prepared for planted rice microcosms: 16 pots for the unamended control, and 16 pots each for RS treatment I and RS treatment II. For both RS treatments, $10 \mathrm{~g}$ powder of RS was added to each pot and mixed thoroughly. The $\delta^{13} \mathrm{C}$ values of RS added in treatment I and II were $213.0 \%$ and $474.7 \%$ o, respectively. These $\delta^{13} \mathrm{C}$ values were obtained by mixing ${ }^{13} \mathrm{C}$-labeled $\left(\delta^{13} \mathrm{C}=\right.$ $1859.9 \%$ o $)$ and unlabeled $\left(\delta^{13} \mathrm{C}=-27.6 \%\right.$ o $)$ RS. The $\delta^{13} \mathrm{C}$ values of these RS mixtures were always higher than those of the produced $\mathrm{CH}_{4}$ and $\mathrm{CO}_{2}$, even when these gases were almost exclusively (90-100\%) produced from the added RS. Therefore, the RS mixtures were sufficiently homogeneous to prevent preferential decomposition of ${ }^{13} \mathrm{C}$-labeled (and presumably labile) components of RS. After 3 days of incubation in the greenhouse, all the pots were planted with one 12-day-old rice seedling (Oryza sativa var. KORAL type japonica), and were flooded with demineralized water to give a water depth of $5 \mathrm{~cm}$ above the soil surface. The water depth was maintained throughout the experimental period. The rice microcosms were incubated in the greenhouse with a relative humidity of $70 \%$, a $12 \mathrm{~h}$ photoperiod and a $28 / 22^{\circ} \mathrm{C}$ day/night temperature cycle. The day of transplantation was taken as day zero. At each sampling time (day 41, 55, 70 and 90), 12 rice microcosms were sacrificed (4 replicates for control and for each treatment). For unplanted microcosms, the preparation was the same as for planted ones, but without rice plant in the pots. In total, 12 pots were prepared with 4 pots each for the unamended control, RS treatment I and RS treatment II.

\subsection{2 $\mathrm{CH}_{4}$ flux and production rates}

Rates of $\mathrm{CH}_{4}$ emission were measured on day 41, 55, 70 and 90 of incubation in the greenhouse. For flux measurements, planted rice microcosms were covered by flux chambers, and gas samples were taken every $30 \mathrm{~min}$ for $2 \mathrm{~h} . \mathrm{CH}_{4}$ emission rates were determined from the slope of the linearly increasing $\mathrm{CH}_{4}$ mixing ratio and expressed in $\mathrm{mmol} \mathrm{CH}_{4} \mathrm{~m}^{-2} \mathrm{~h}^{-1}$.

Production rates of $\mathrm{CH}_{4}$ and respective $\delta^{13} \mathrm{C}$ values were determined by collecting soil core samples in rice microcosms on day 41, 55, 70 and 90 of incubation in the greenhouse (Krüger et al., 2001; Yuan et al., 2012). After cutting off the rice plant, the surface water layer was removed. Soil cores were taken with a stainless steel corer $(22 \mathrm{~mm}$ in diameter, $210 \mathrm{~mm}$ in length). Two to three soil cores (about $100 \mathrm{~g}$ in total) were collected from each pot and transferred into a $250 \mathrm{~mL}$ bottle. The soil samples were turned into slurry using $\mathrm{N}_{2}$-gassed deionized sterile water so that the ratio of dry weight of soil to water was $1: 1$. After flushing the samples with $\mathrm{N}_{2}$, the bottles were sealed with rubber stoppers and, after shaking, flushed again with $\mathrm{N}_{2}$ to remove residual $\mathrm{O}_{2}$ and $\mathrm{CH}_{4}$. Incubation was performed statically at $25^{\circ} \mathrm{C}$ in darkness for $24 \mathrm{~h}$. Headspace samples were taken every $12 \mathrm{~h}$ after shaking the bottles, and analyzed for concentration of $\mathrm{CH}_{4}$ and $\delta^{13} \mathrm{C}$ of $\mathrm{CH}_{4}$. The $\mathrm{CH}_{4}$ production from planted soil microcosms was due to decomposition of SOM plus ROC (unamended control) or of SOM, ROC plus RS (RS treatments). $\mathrm{CH}_{4}$ production rates were calculated by linear regression of the $\mathrm{CH}_{4}$ increase with incubation time, and expressed in nmol CH $4 g_{d w}^{-1} h^{-1}$ of soil.

For unplanted soil microcosms, the methods for collection and incubation of soil core samples were similar, but these pots were not sacrificed. At each sampling day (day 41, 55, 70 and 90), a $60 \mathrm{~g}$ soil core was taken from the pot. After removal of the soil core the residual soil in the pot was compacted, and water was added to maintain a water level of $5 \mathrm{~cm}$ depth. Using this procedure about $2.1 \%$ of the total amount of soil in the pot was collected during each sampling. The $\mathrm{CH}_{4}$ production from unplanted soil microcosms was only due to decomposition of SOM (unamended control) and of SOM plus RS (RS treatments). 
During each sampling, small amounts of soil were collected from the homogenized soil cores before anoxic incubation and stored at $-80^{\circ} \mathrm{C}$ for later molecular analysis.

\subsection{Laboratory incubation of soil with RS application}

After $0.5 \mathrm{~mm}$ sieving, $5 \mathrm{~g}$ dry Vercelli soil was mixed with $5 \mathrm{~mL}$ anoxic water in $26 \mathrm{~mL}$ pressure tubes. Tubes were closed with butyl rubber stoppers, sealed with aluminum crimps, then flushed with $\mathrm{N}_{2}$ and incubated statically at $25^{\circ} \mathrm{C}$ in darkness. RS treatments I and II were done at the beginning of the anoxic incubation or after 40 days. The $\delta^{13} \mathrm{C}$ values of RS added in treatment I and II were $596.1 \%$ and $885.0 \%$, respectively. The preparation of RSI and RSII was as described above. For RS treatments at the beginning of anoxic incubation, $25 \mathrm{mg}(0.5 \%)$ unlabeled RS or labeled RS (RSI or RSII) powder was added to each tube. For RS treatments after 40 days of anoxic incubation, $5 \mathrm{mg}(0.1 \%)$ or $10 \mathrm{mg}(0.2 \%) \mathrm{RSI}$ or RSII powder was added to each tube. Immediately after RS addition, the tubes were sealed again and flushed with $\mathrm{N}_{2}$ and, after shaking, re-flushed with $\mathrm{N}_{2}$ to remove the residual $\mathrm{O}_{2}$ and $\mathrm{CH}_{4}$. Then the tubes were incubated statically at $25^{\circ} \mathrm{C}$. Besides the RS treatments, methyl fluoride $\left(\mathrm{CH}_{3} \mathrm{~F}\right)$ was added to the headspace of several incubation batches to give the desired concentration of $1.0 \%$. All the treatments were prepared in triplicates. After RS application in each RS treatment, the RS-derived $\mathrm{CH}_{4}$ and $\mathrm{CO}_{2}$ production rate was calculated by linear regression of the $\mathrm{CH}_{4}$ and $\mathrm{CO}_{2}$ increase from RS within 3 days, and expressed in nmol $\mathrm{CH}_{4}$ or $\mathrm{CO}_{2} \mathrm{~h}^{-1} \mathrm{~g}_{\mathrm{dw}}^{-1}$ of soil. The calculations of $\mathrm{CH}_{4}$ and $\mathrm{CO}_{2}$ derived from $\mathrm{RS}$ were done as explained below.

\subsection{Analytical techniques}

The gas samples were analyzed for $\mathrm{CH}_{4}$ and $\mathrm{CO}_{2}$ using a gas chromatograph (GC) equipped with flame ionization detector (FID) (Bodelier et al., 2000). Stable isotopic analyses of $\mathrm{CH}_{4}$ and $\mathrm{CO}_{2}$ were performed using a gas chromatograph combustion isotope ratio mass spectrometer (GC-C-IRMS) (Finnigan, Bremen, Germany) (Penning and Conrad, 2007). The determination of the stable isotopic signatures of dried plant (RS) and soil samples (SOM) was carried out at the Institute of Soil Science and Forest Nutrition (IBW) at the University of Göttingen, Germany.

\subsection{Quantification of microbial abundance}

DNA from the soil samples was extracted according to the lysis protocol described in the NucleoSpin ${ }^{\circledR}$ soil kit (Macherey-Nagel, Germany). Quantifications of bacterial 16S rRNA gene and gene (mcrA) coding for a subunit of the methyl coenzyme $\mathrm{M}$ reductase were done via iCycler Thermal Cycler (Bio-Rad, Germany) using SYBR ${ }^{\circledR}$ Green JumpStart $^{\mathrm{TM}}$ Taq ReadyMix ${ }^{\mathrm{TM}}$ (Sigma). This enzyme is characteristic and unique for methanogenic Archaea. For the quantitative polymerase chain reaction (PCR) of bacterial
16S rRNA, the primer pair (519f and 907r) and parameters followed the protocol described in Stubner (2002), for mcrA gene, the primer pair (mlas-mod and mcrA-rev), and parameters followed the protocol described in Angel et al. (2011). The gene copy numbers detected are a proxy for the abundance of the respective microbes.

\subsection{Calculations}

\subsubsection{Fraction of $\mathrm{CH}_{4}$ production from $\mathrm{ROC}\left(f_{\mathrm{ROC}}\right)$, RS carbon $\left(f_{\mathrm{RS}}\right)$ and SOM $\left(f_{\mathrm{SOM}}\right)$ in planted rice microcosms with $\mathrm{RS}$ application}

The fraction of $\mathrm{CH}_{4}$ derived from ROC $\left(f_{\mathrm{ROC}}\right)$ can be determined from the following mass balance equation:

$\delta^{13} \mathrm{C}_{\mathrm{CH}_{4}}=f_{\mathrm{ROC}} \delta^{13} \mathrm{C}_{\mathrm{CH}_{4}-\mathrm{ROC}}+\left(1-f_{\mathrm{ROC}}\right) \delta^{13} \mathrm{C}_{\mathrm{CH}_{4}-\mathrm{SOR}}$,

where $\delta^{13} \mathrm{C}_{\mathrm{CH}_{4}}=\delta^{13} \mathrm{C}$ of $\mathrm{CH}_{4}$ produced in the planted rice microcosms at each sampling time; $\delta^{13} \mathrm{C}_{\mathrm{CH}_{4}-\mathrm{ROC}}=$ $\delta^{13} \mathrm{C}$ of $\mathrm{CH}_{4}$ formed from ROC (determination see below); $\delta^{13} \mathrm{C}_{\mathrm{CH}_{4} \text {-SOR }}=\delta^{13} \mathrm{C}$ of $\mathrm{CH}_{4}$ formed from SOM plus RS (i.e., the $\mathrm{CH}_{4}$ produced in the unplanted soil treated with RS). The equation can be transformed into the following two equations for RS treatment I and II, respectively:

$$
\begin{aligned}
f_{\mathrm{ROC}}= & \left(\delta^{13} \mathrm{C}_{\mathrm{CH}_{4} \text {-I }}-\delta^{13} \mathrm{C}_{\mathrm{CH}_{4} \text {-SOR-I }}\right) / \\
& \left(\delta^{13} \mathrm{C}_{\mathrm{CH}_{4}-\mathrm{ROC}}-\delta^{13} \mathrm{C}_{\mathrm{CH}_{4} \text {-SOR-I I }}\right), \\
f_{\mathrm{ROC}}= & \left(\delta^{13} \mathrm{C}_{\mathrm{CH}_{4} \text {-II }}-\delta^{13} \mathrm{C}_{\mathrm{CH}_{4} \text {-SOR-II }}\right) / \\
& \left(\delta^{13} \mathrm{C}_{\mathrm{CH}_{4} \text {-ROC }}-\delta^{13} \mathrm{C}_{\mathrm{CH}_{4} \text {-SOR-II }}\right) .
\end{aligned}
$$

Since $f_{\mathrm{ROC}}$ and $\delta^{13} \mathrm{C}_{\mathrm{CH}_{4} \text {-ROC }}$ should be the same in treat-

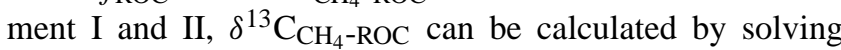
Eqs. (2) and (3). Then, $f_{\text {ROC }}$ can be calculated from either Eqs. (2) or (3). The fraction of $\mathrm{CH}_{4}$ derived from RS ( $\left.f_{\mathrm{RS}}\right)$ can be determined from the following mass balance equation:

$$
\begin{aligned}
f_{\mathrm{RS}}= & \left(\delta^{13} \mathrm{C}_{\mathrm{CH}_{4}-\mathrm{I}}-\delta^{13} \mathrm{C}_{\mathrm{CH}_{4}-\mathrm{II}}\right) / \\
& \left(\delta^{13} \mathrm{C}_{\mathrm{RS}-\mathrm{I}}-\delta^{13} \mathrm{C}_{\mathrm{RS}-\mathrm{II}}\right),
\end{aligned}
$$

of which $\delta^{13} \mathrm{C}_{\mathrm{CH}_{4} \text {-I }}$ and $\delta^{13} \mathrm{C}_{\mathrm{CH}_{4} \text {-II }}$ were determined experimentally, and RS-I and RS-II were mixtures of labeled and unlabeled RS, of which the $\delta^{13} \mathrm{C}$ were determined experimentally. Details of calculations of $f_{\mathrm{ROC}}$ and $f_{\mathrm{RS}}$ have been described previously (Yuan et al., 2012). Finally, the fraction of $\mathrm{CH}_{4}$ production from SOM ( $\left.f_{\text {SOM }}\right)$ can be calculated, since

$f_{\mathrm{RS}}+f_{\mathrm{ROC}}+f_{\mathrm{SOM}}=1$.

\subsection{2 $\mathrm{CH}_{4}$ production rates from SOM and ROC in planted rice microcosms with $\mathrm{RS}$ application}

The effect of RS on $\mathrm{CH}_{4}$ production from SOM and ROC was determined in the RS treatments with rice plants. The 
rates of $\mathrm{CH}_{4}$ production from $\mathrm{ROC}\left(p_{\mathrm{ROC}, \mathrm{CH}_{4}}\right)$ and from $\mathrm{SOM}\left(p_{\mathrm{SOM}_{2} \mathrm{CH}_{4}}\right)$ were calculated from the total $\mathrm{CH}_{4}$ production rates $\left(p_{\mathrm{CH}_{4}}\right)$ and the fractions of $\mathrm{CH}_{4}$ production from $\mathrm{ROC}\left(f_{\mathrm{ROC}}\right)$ and $\mathrm{SOM}\left(f_{\mathrm{SOM}}\right)$ as below:

$p_{\mathrm{ROC}, \mathrm{CH}_{4}}=f_{\mathrm{ROC}} p_{\mathrm{CH}_{4}}$,

$p_{\mathrm{SOM}, \mathrm{CH}_{4}}=f_{\mathrm{SOM}} p_{\mathrm{CH}_{4}}$.

\subsubsection{Contribution of $\mathrm{RS}$ and SOM to $\mathrm{CH}_{4}$ in soil slurries with RS application}

The $\delta^{13} \mathrm{C}$ values of the $\mathrm{CH}_{4}$ produced in the two RS treatments are given by the following two mass balance equations:

$\delta^{13} \mathrm{C}_{\mathrm{CH}_{4}-\mathrm{I}}=f_{\mathrm{RS}} \delta^{13} \mathrm{C}_{\mathrm{RS}-\mathrm{I}}+f_{\mathrm{SOM}} \delta^{13} \mathrm{C}_{\mathrm{SOM}}+\Delta \mathrm{CH}_{4}$,

$\delta^{13} \mathrm{C}_{\mathrm{CH}_{4}-\mathrm{II}}=f_{\mathrm{RS}} \delta^{13} \mathrm{C}_{\mathrm{RS}-\mathrm{II}}+f_{\mathrm{SOM}} \delta^{13} \mathrm{C}_{\mathrm{SOM}}+\Delta \mathrm{CH}_{4}$,

with $f_{\mathrm{RS}}$ and $f_{\mathrm{SOM}}$ denoting fractions of $\mathrm{CH}_{4}$ produced from RS and SOM, respectively; $\delta^{13} \mathrm{C}_{\mathrm{RS}-\mathrm{I}}$ and $\delta^{13} \mathrm{C}_{\mathrm{RS}-\mathrm{II}}$ are $\delta^{13} \mathrm{C}$ of the rice straw carbon in treatment I $(596.1 \%$ o) and II $\left(885.0 \%\right.$ ) , respectively; $\delta^{13} \mathrm{C}_{\mathrm{SOM}}$ is $\delta^{13} \mathrm{C}$ of SOM $(-25.8 \%$ o $), \Delta \mathrm{CH}_{4}$ designates the overall isotopic enrichment factors involved in the conversion of RS and SOM to $\mathrm{CH}_{4}$. Since the terms $f_{\mathrm{SOM}} \delta^{13} \mathrm{C}_{\mathrm{SOM}}$ and $\Delta \mathrm{CH}_{4}$ should be the same in treatment I and II, the combination of Eqs. (3) and (4) and solving for $f_{\mathrm{RS}}$ results in

$$
\begin{aligned}
f_{\mathrm{RS}}= & \left(\delta^{13} \mathrm{C}_{\mathrm{CH}_{4}-\mathrm{I}}-\delta^{13} \mathrm{C}_{\mathrm{CH}_{4}-\mathrm{II}}\right) / \\
& \left(\delta^{13} \mathrm{C}_{\mathrm{RS}-\mathrm{I}}-\delta^{13} \mathrm{C}_{\mathrm{RS}-\mathrm{II}}\right),
\end{aligned}
$$

of which $\delta^{13} \mathrm{C}$ can be determined experimentally. Here, $\delta^{13} \mathrm{C}_{\mathrm{CH}_{4} \text {-I }}$ and $\delta{ }^{13} \mathrm{C}_{\mathrm{CH}_{4} \text {-II }}$ were determined experimentally, and RS-I and RS-II were mixtures of labeled and unlabeled $\mathrm{RS}$, of which the $\delta^{13} \mathrm{C}$ were determined experimentally (see above). Finally, the fraction of $\mathrm{CH}_{4}$ production from SOM $\left(f_{\text {SOM }}\right)$ can be calculated, since

$f_{\mathrm{RS}}+f_{\mathrm{SOM}}=1$.

Then, the amount of $\mathrm{CH}_{4}$ production from $\mathrm{RS}\left(p_{\mathrm{RS}, \mathrm{CH}_{4}}\right)$ and from SOM $\left(p_{\mathrm{SOM}, \mathrm{CH}_{4}}\right)$ was calculated from the total amount of $\mathrm{CH}_{4}$ produced $\left(p_{\mathrm{CH}_{4}}\right)$ and the fractions of $\mathrm{CH}_{4}$ production from $\operatorname{ROC}\left(f_{\mathrm{RS}}\right)$ and $\mathrm{SOM}\left(f_{\mathrm{SOM}}\right)$ :

$p_{\mathrm{RS}, \mathrm{CH}_{4}}=f_{\mathrm{RS}} p_{\mathrm{CH}_{4}}$,

$p_{\mathrm{SOM}, \mathrm{CH}_{4}}=f_{\mathrm{SOM}} p_{\mathrm{CH}_{4}}$.

Analogous equations are valid for the fractions and amount of $\mathrm{CO}_{2}$ produced from RS and SOM in rice soil.

\subsubsection{Amount and $\delta^{13} \mathrm{C}$ of total inorganic carbon (TIC)}

Total amounts of gases in the headspace of the tubes were calculated from the partial pressures using the volume of the gas space and the gas constant. The amounts of $\mathrm{CH}_{4}$ dissolved in the liquid were less than $3 \%$ of the total and were neglected. The amounts of $\mathrm{CO}_{2}$ (aq) dissolved in the liquid were calculated from the solubility constant of $\mathrm{CO}_{2}$ $\left(1 \times 10^{-1.47} \mathrm{~mol} \mathrm{~L}^{-1} \mathrm{bar}^{-1}\right)$, those of bicarbonate $\left(\mathrm{HCO}_{3}^{-}\right)$ from the solubility constant of $\mathrm{CO}_{2}$, the $\mathrm{pH}$ (measured), and the dissociation constant $\left(10^{-6.35}\right)$ of bicarbonate (Stumm and Morgan, 1981). Total inorganic carbon (TIC) was defined as the sum of bicarbonate, gaseous, and dissolved $\mathrm{CO}_{2}$. The $\delta^{13} \mathrm{C}$ of dissolved $\mathrm{CO}_{2}\left(\alpha_{\mathrm{CO}_{2}(\mathrm{aq})}=0.9990\right)$ and bicarbonate $\left(\alpha_{\mathrm{HCO}_{3}}=1.0075\right)$ were calculated from the $\delta^{13} \mathrm{C}$ of gaseous $\mathrm{CO}_{2}$ and the corresponding fractionation factors $\alpha$ (Stumm and Morgan, 1981), which are

$$
\begin{aligned}
& \alpha_{\mathrm{CO}_{2}(\mathrm{aq})}=\left(\delta^{13} \mathrm{C}_{\mathrm{CO}_{2}(\mathrm{aq})}+1000\right) /\left(\delta^{13} \mathrm{C}_{\mathrm{CO}_{2}(\mathrm{~g})}+1000\right), \\
& \alpha_{\mathrm{HCO}_{3}}=\left(\delta^{13} \mathrm{C}_{\mathrm{HCO}_{3}}+1000\right) /\left(\delta^{13} \mathrm{C}_{\mathrm{CO}_{2}(\mathrm{~g})}+1000\right) .
\end{aligned}
$$

The values of $\delta^{13} \mathrm{C}_{\mathrm{CO}_{2}(\mathrm{~g})}, \delta^{13} \mathrm{C}_{\mathrm{CO}_{2}(\mathrm{aq})}$, and $\delta^{13} \mathrm{C}_{\mathrm{HCO}_{3}}$ were used to calculate $\delta^{13} \mathrm{C}_{\text {TIC }}$ using the mole fractions of the different $\mathrm{CO}_{2}$ species (Penning and Conrad, 2006).

\subsection{Statistical analysis}

The significance of differences between treatments over time for various variables was determined by one-way analysis of variance (ANOVA) followed by multiple comparisons (Duncan's post hoc test) using SPSS 13.0. To test the significance of the differences between control and RS treatment on $\mathrm{CH}_{4}$ or TIC production from SOM, two-tailed independent $t$ tests were applied using Microsoft Excel 2007.

\section{Results}

\subsection{Enhancement of $\mathrm{CH}_{4}$ production from both $\mathrm{SOM}$ and ROC by RS application in planted rice microcosms}

Application of rice straw increased the rates of both $\mathrm{CH}_{4}$ production and $\mathrm{CH}_{4}$ emission in a proportional way (Fig. 1). In the rice microcosms without $\mathrm{RS}, \mathrm{CH}_{4}$ production rates increased from the tillering stage (day 41) to the booting stage (day 55) and the flowering stage (day 70), then peaked at the ripening stage (day 90) (Table 1). Methane production rates were increased by RS application throughout the growth period, but particularly during the tillering and booting stages. The $\delta^{13} \mathrm{C}$ values of the $\mathrm{CH}_{4}$ produced in microcosms amended with ${ }^{13} \mathrm{C}$-labeled $\mathrm{RS}$ were used for calculation of the fractions of total $\mathrm{CH}_{4}$ derived from RS, ROC and SOM. ROC was found to make a major contribution (41$63 \%)$ to $\mathrm{CH}_{4}$ production over the entire vegetation period. 
Table 1. $\mathrm{CH}_{4}$ production rates in soil sampled from microcosms with and without rice plant and rice straw $(\mathrm{RS})$, mean \pm SD $(n=4)$.

\begin{tabular}{|c|c|c|c|c|c|c|}
\hline Time (days) & $\begin{array}{c}(\mathrm{A})^{\mathrm{a}} \\
\text { Planted soil } \\
\text { without RS } \\
\left(\mathrm{nmol} \mathrm{g}_{\mathrm{dw}}^{-1} \mathrm{~h}^{-1}\right)\end{array}$ & $\begin{array}{c}(\mathrm{B})^{\mathrm{a}} \\
\text { Planted soil } \\
\text { with RS } \\
\left(\mathrm{nmol} \mathrm{g}_{\mathrm{dw}}^{-1} \mathrm{~h}^{-1}\right)\end{array}$ & $\begin{array}{c}(\mathrm{C})^{\mathrm{a}} \\
\text { Unplanted soil } \\
\text { without RS } \\
\left(\text { nmol g }_{\mathrm{dw}}^{-1} \mathrm{~h}^{-1}\right)\end{array}$ & $\begin{array}{c}(\mathrm{D})^{\mathrm{a}} \\
\text { Unplanted soil } \\
\text { with RS } \\
\left(\mathrm{nmol} \mathrm{g}_{\mathrm{dw}}^{-1} \mathrm{~h}^{-1}\right)\end{array}$ & $\begin{array}{c}\mathrm{A}-\mathrm{C}^{\mathrm{b}} \\
\left(\mathrm{nmol} \mathrm{g} \mathrm{g}_{\mathrm{dw}}^{-1}\right. \\
\left.\mathrm{h}^{-1}\right)\end{array}$ & $\begin{array}{c}\mathrm{B}-\mathrm{D}^{\mathrm{b}} \\
\left(\mathrm{nmol} \mathrm{g} \mathrm{g}_{\mathrm{dw}}^{-1}\right. \\
\left.\mathrm{h}^{-1}\right)\end{array}$ \\
\hline 41 & $5.5 \pm 1.0$ & $58.1 \pm 11.2^{* *}$ & $0.1 \pm 0.0$ & $21.3 \pm 2.3$ & $5.4 \pm 1.0$ & $36.9 \pm 11.4^{\#}$ \\
\hline 55 & $13.0 \pm 1.3$ & $41.8 \pm 2.5^{* *}$ & $2.4 \pm 0.9$ & $21.5 \pm 2.1$ & $10.6 \pm 1.6$ & $20.2 \pm 3.3^{\# \#}$ \\
\hline 70 & $16.1 \pm 4.5$ & $33.4 \pm 11.7^{*}$ & $3.9 \pm 2$ & $20.1 \pm 1.2$ & $12.2 \pm 4.9$ & $13.2 \pm 11.8$ \\
\hline 90 & $25.1 \pm 1.1$ & $42.1 \pm 10.4^{*}$ & $3.6 \pm 0.4$ & $10.4 \pm 2.1$ & $21.6 \pm 1.1$ & $31.7 \pm 10.6$ \\
\hline
\end{tabular}

a Data taken from Yuan et al. (2012).

$\mathrm{b}$ The values give the apparent contribution of rice plants to $\mathrm{CH}_{4}$ production in microcosms without $(\mathrm{A}-\mathrm{C})$ and with $(\mathrm{B}-\mathrm{D})$ rice straw. The differences between planted soil without (A) and with RS (B) were tested by two-tailed independent $t$ test, indicated by ** when $P<0.01$ or $*$ when $P<0.05$. The differences between A-C and B-D were also tested with two-tailed independent $t$ test, indicated by ${ }^{\# \#}$ when $P<0.01$ or ${ }^{\#}$ when $P<0.05$.

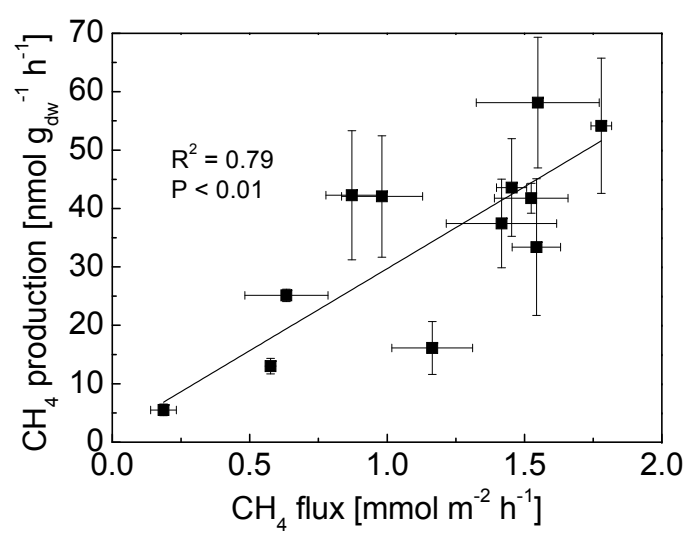

Fig. 1. Rates of $\mathrm{CH}_{4}$ production and $\mathrm{CH}_{4}$ emission measured during incubation of planted rice microcosms without and with addition of rice straw; means $\pm \mathrm{SD}(n=4)$.

SOM contributed about $23-35 \%$, and RS accounted for the rest (12-24\%) (Yuan et al., 2012).

Knowing the percentage contribution of SOM and ROC and the total $\mathrm{CH}_{4}$ production rates, the individual production rates of $\mathrm{CH}_{4}$ from ROC ( $p_{\mathrm{ROC}}$ ) and SOM ( $p_{\mathrm{SOM}}$ ) could be calculated in the RS-treated microcosms (Fig. 2a). Production rates of total $\mathrm{CH}_{4}$ were also determined for unamended control microcosms, in which $\mathrm{CH}_{4}$ was produced from ROC and SOM only. The results showed that SOM-derived plus ROC-derived $\mathrm{CH}_{4}$ production rates were higher in the RStreated microcosms than in the untreated controls during the entire vegetation season. Specifically at the tillering stage, both the SOM-derived and the ROC-derived $\mathrm{CH}_{4}$ production rates were increased in the presence of RS. At the booting stage, the ROC-derived $\mathrm{CH}_{4}$ production was still substantially increased (Fig. 2a). Hence, the RS treatment exerted a positive feedback on the $\mathrm{CH}_{4}$ production from SOM and ROC. The positive feedback on $\mathrm{CH}_{4}$ production from ROC after RS application was consistent with mass balance calculations of $\mathrm{CH}_{4}$ production in microcosms that were planted or unplanted and treated or untreated with RS (Table 1).
Microcosms treated with RS exhibited a higher abundance of mcrA copies than untreated microcosms, and planted microcosms generally contained more mcrA copies than unplanted ones (Fig. 2b). By contrast, addition of RS did not significantly affect the abundance of Bacteria (Fig. 2c).

\subsection{Stimulation of $\mathrm{CH}_{4}$ production from $\mathrm{SOM}$ by $\mathrm{RS}$ application in soil slurry}

Rice field soil was amended with $0.5 \%{ }^{13} \mathrm{C}$-labeled RS I or II and then preincubated for 40 days under anoxic conditions to ensure that soil conditions were reduced and methanogenesis was the exclusive terminal decomposition process of organic matter. Methane production was higher in the RS-treated soil than in the untreated control (Fig. 3a). The SOM-derived $\mathrm{CH}_{4}$ production after 40 days of anoxic pre-incubation was calculated from the amount (Fig. 3a) and $\delta^{13} \mathrm{C}$ (Fig. 3b) of the released $\mathrm{CH}_{4}$ using Eq. (13). The results showed that $\mathrm{CH}_{4}$ production from SOM was always higher in the RS-treated than in the untreated control soil (Fig. 3c).

In a second experiment, unamended rice field soil was preincubated for 40 days under anoxic conditions and then treated with either $0.1 \%$ or $0.2 \%{ }^{13} \mathrm{C}$-labeled RS. Methane production rates were higher in the RS-treated soil than in the untreated control and were higher in the treatment with $0.2 \%$ than $0.1 \%$ RS (Fig. 4a). After about 10 days of anaerobic decomposition of $\mathrm{RS}$, the accumulated $\mathrm{CH}_{4}$ derived from $\mathrm{SOM}$ was higher in the RS treatments than in the untreated control and further increased gradually afterwards (Fig. 4b). The stimulation of SOM degradation by RS was also seen when methanogenesis was partially inhibited by $\mathrm{CH}_{3} \mathrm{~F}$, a specific inhibitor of aceticlastic methanogenesis (Janssen and Frenzel, 1997) (Fig. 4c). The residual $\mathrm{CH}_{4}$ production observed in the presence of $\mathrm{CH}_{3} \mathrm{~F}$ was assigned to hydrogenotrophic methanogenesis. While hydrogenotrophic methanogenesis accounted for about $25 \%$ of total $\mathrm{CH}_{4}$ production in the untreated control soil, it accounted for about $50 \%$ in the RS treatment, indicating that RS stimulated hydrogenotrophic methanogenesis in particular. Carbon dioxide (quantified as 

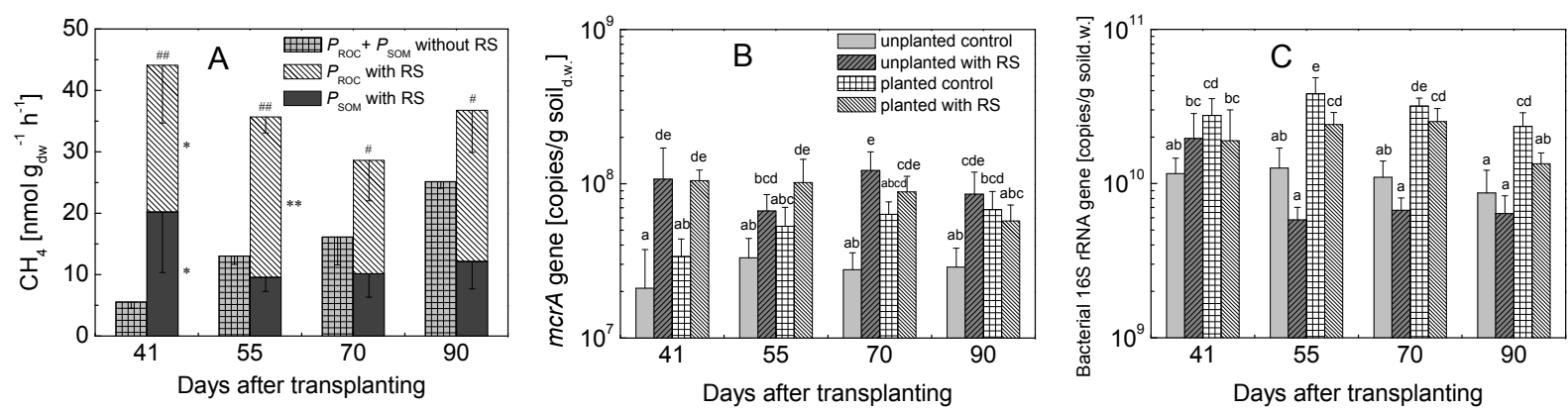

Fig. 2. Production rates of $\mathrm{CH}_{4}$ and abundance of methanogens and Bacteria in planted microcosms without and with RS application. (A) Individual $\mathrm{CH}_{4}$ production derived from $\mathrm{ROC}\left(p_{\mathrm{ROC}}\right)$ and $\mathrm{SOM}\left(p_{\mathrm{SOM}}\right)$ with $\mathrm{RS}$ application compared to total $\mathrm{CH}_{4}$ production $\left(p_{\mathrm{ROC}}+\right.$ $\left.p_{\mathrm{SOM}}\right)$ without RS addition. The differences between $p_{\mathrm{ROC}}+p_{\mathrm{SOM}}$ without RS and $p_{\mathrm{ROC}}$ or $p_{\mathrm{SOM}}$ with RS were tested by one-tailed independent $t$ test, indicated beside the bars by ${ }^{* *}$ when $P<0.01$ or $*$ when $P<0.05$. The differences between $p_{\mathrm{ROC}}+p_{\mathrm{SOM}}$ without and with RS were tested as described above, indicated on the top of the bars by \#\# when $P<0.01$ or \# when $P<0.05$; (B) mcrA gene (characteristic for methanogenic Archaea) and (C) bacterial 16S rRNA gene copy numbers without and with RS application; means \pm SD $(n=4)$. The differences between the treatments over time were examined using Duncan's post hoc test of a one-way analysis of variance (ANOVA). Different letters on the top of bars indicate significant difference $(P<0.05)$ between the data.
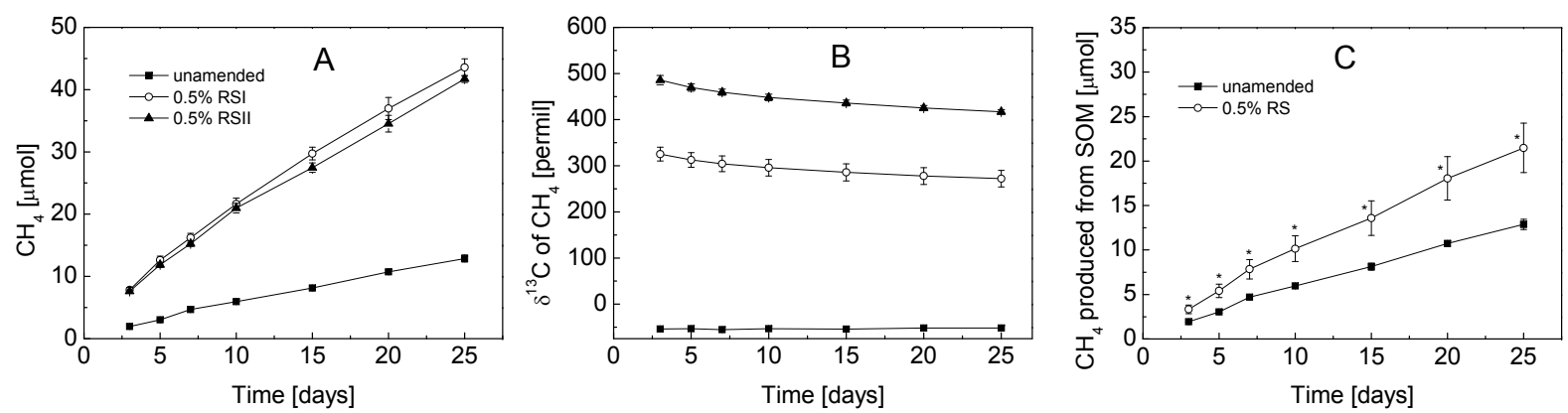

Fig. 3. Production of $\mathrm{CH}_{4}(\mathbf{A}), \delta^{13} \mathrm{C}$ value of produced $\mathrm{CH}_{4}(\mathbf{B})$ and $\mathrm{SOM}$-derived $\mathrm{CH}_{4}$ production $(\mathbf{C})$ in control soil and treatments with $0.5 \%{ }^{13} \mathrm{C}$-labeled RS I or II after 40 days of anoxic pre-incubation. The RS was applied at the beginning of anoxic incubation. The headspace of all bottles was re-flushed with $\mathrm{N}_{2}$ after 40 days of anoxic incubation. Therefore, "day 0" on the $x$ axis corresponds to the actual date of "day 40" in the entire incubation period. Data are means $\pm \mathrm{SD}(n=3)$. The differences between control and RS treatment in SOM-derived $\mathrm{CH}_{4}$ production were tested by two-tailed independent $t$ test, indicated by ${ }^{*}$ when $P<0.05$.

TIC) is besides $\mathrm{CH}_{4}$ the end product of anaerobic degradation of organic matter. At the end of incubation (day 25), there were no significant differences in the total amount of $\mathrm{CH}_{4}$ plus TIC derived from SOM between RS treatments and control (Fig. 4d).

\subsection{Methanogenic decomposition of $\mathrm{RS}$ in anoxic soil slurry with different abundance of methanogenic community}

Degradation of RS was studied in soil that had or had not previously been treated with RS. For this purpose, control soil or soil amended with $0.5 \%$ unlabeled RS was again treated with $0.1 \%$ or $0.2 \%{ }^{13} \mathrm{C}$-labeled RS. The production rates of TIC and $\mathrm{CH}_{4}$ derived from the newly applied RS were calculated from the total production rates of TIC and $\mathrm{CH}_{4}$ and their $\delta^{13} \mathrm{C}$ values. The results showed that previous RS treatment resulted in strong increase (at least doubling) of the pro- duction rates of both TIC and $\mathrm{CH}_{4}$ derived from newly applied ROC (Table 2). In addition, the larger amount of newly added RS also resulted in a proportionally larger amount of RS-derived TIC and $\mathrm{CH}_{4}$ produced (Table 2).

\section{Discussion}

\subsection{Reliability of design and calculations used for the rice microcosm experiments}

Isotopic discrimination of ${ }^{13} \mathrm{C}$ occurs in production, consumption and transport processes of $\mathrm{CH}_{4}$ in rice field soil, all of which are sensitive to chemical and physical conditions, and these conditions could be different in the presence and absence of plants. Therefore, we did not use the $\delta^{13} \mathrm{C}$ of the $\mathrm{CH}_{4}$ that was emitted from the microcosms, but instead collected soil cores and incubated them under anoxic conditions. Prior to incubation, the $\mathrm{CH}_{4}$ accumulated was 

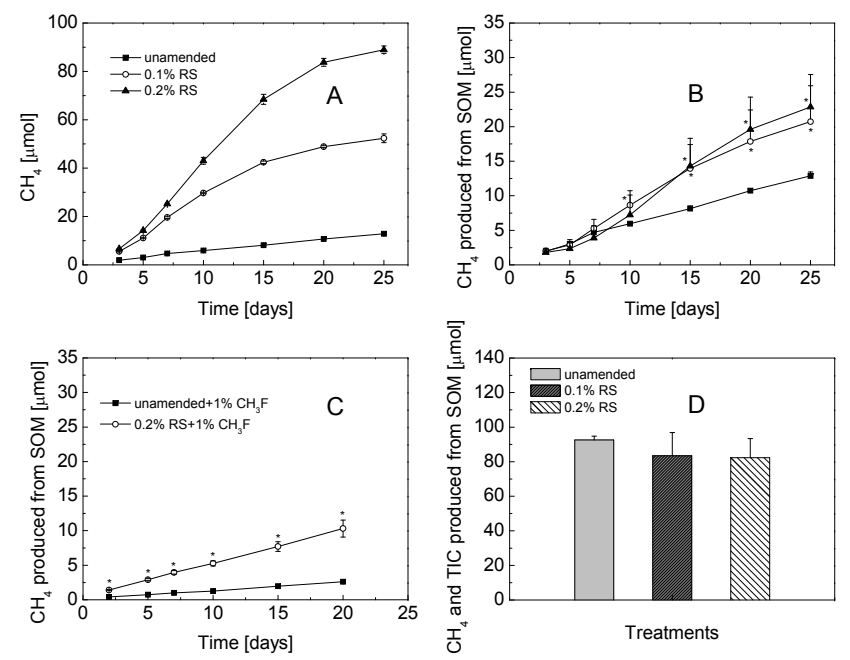

Fig. 4. Production of $\mathrm{CH}_{4}$ (A), SOM-derived $\mathrm{CH}_{4}$ production (B), SOM-derived $\mathrm{CH}_{4}$ production in the presence of $1 \% \mathrm{CH}_{3} \mathrm{~F}(\mathbf{C})$ and total amount of SOM-derived $\mathrm{CH}_{4}$ and TIC (D) in control soil and treatments with $0.1 \%$ or $0.2 \%{ }^{13} \mathrm{C}$-labeled RS I or II. The RS was applied after 40 days of anoxic pre-incubation of rice soil, and then the headspace of all bottles was re-flushed with $\mathrm{N}_{2}$. Therefore, "day 0" on the $x$ axis corresponds to the actual date of "day 40" in the entire incubation period. Data are means $\pm \mathrm{SD}(n=3)$. The total amount of SOM-derived $\mathrm{CH}_{4}$ and TIC were calculated at day 25 after RS application. The differences between control and RS treatments were tested by two-tailed independent $t$ test only in (B) and (D), indicated by * when $P<0.05$.

removed so that the $\delta^{13} \mathrm{C}$ of the $\mathrm{CH}_{4}$ measured was that of newly produced $\mathrm{CH}_{4}$ and unbiased from isotope fractionation other than during $\mathrm{CH}_{4}$ production. The soil was sampled from rice pots after cutting off the rice plant. Therefore the carbon flow from the root (ROC) into the soil was interrupted and could have resulted in underestimation of $\mathrm{CH}_{4}$ production. However, our measurement period was short $(24 \mathrm{~h})$ to avoid depletion of root exudates previously excreted and of cut roots. Literature data (Lu et al., 2000) and our own experience indicate that $\mathrm{CH}_{4}$ production rates under such conditions cover methanogenesis from root exudates quite well. Indeed, the $f_{\mathrm{ROC}}$ measured by this procedure was $41-63 \%$ and thus quite high. Therefore, the measurement procedure most probably did not result in substantial underestimation of $f_{\text {ROC }}$.

The measurement procedure also ensured that variables $\left(\delta^{13} \mathrm{C}_{\mathrm{CH}_{4}}, \delta^{13} \mathrm{C}_{\mathrm{CH}_{4}-\mathrm{ROC}}\right.$ and $\left.\delta^{13} \mathrm{C}_{\mathrm{CH}_{4}-\mathrm{SOR}}\right)$ associated with Eq. (1) were free from isotopic fractionations due to consumption and transport of $\mathrm{CH}_{4}$ and from the influence of formerly accumulated $\mathrm{CH}_{4}$. In addition, there was no significant difference in the abundance of the methanogenic populations between planted and unplanted treatments (abundance of methanogenic community was only enhanced by addition of straw) (Fig. 2b). Therefore, it was reasonable to assume that $\delta^{13} \mathrm{C}_{\mathrm{CH}_{4}-\mathrm{SOR}}$ (the $\delta^{13} \mathrm{C}_{\text {of }} \mathrm{CH}_{4}$ produced from
Table 2. Production rates of TIC and $\mathrm{CH}_{4}$ derived from $0.1 \%$ or $0.2 \%{ }^{13} \mathrm{C}$-labeled RS applied after 40 days of anoxic incubation of untreated control soil or RS-treated soil. For RS-treated soil, rice soil was amended with $0.5 \%$ unlabeled RS at the beginning of anoxic incubation. The headspace of all bottles was re-flushed with $\mathrm{N}_{2}$ after addition of ${ }^{13} \mathrm{C}$-labeled RS. This labeled RS was used as proxy of ROC in this experiment. Data are means $\pm \operatorname{SD}(n=3)$. The differences in $\mathrm{RS}$-derived TIC or $\mathrm{CH}_{4}$ production rates among the treatments were examined using Duncan's post hoc test of ANOVA. Different letters indicate significant difference $(P<0.05)$ between the data.

\begin{tabular}{lrc}
\hline Treatments & $\begin{array}{r}\text { RS-derived TIC } \\
\left(\mathrm{nmol} \mathrm{h}^{-1} \mathrm{~g}^{-1}\right)\end{array}$ & $\begin{array}{r}\text { RS-derived } \mathrm{CH}_{4} \\
\left(\mathrm{nmol} \mathrm{h}^{-1} \mathrm{~g}^{-1}\right)\end{array}$ \\
\hline Control + 0.1\% RS & $23.58 \pm 2.77^{\mathrm{a}}$ & $11.51 \pm 0.57^{\mathrm{a}}$ \\
Control + 0.2\% RS & $55.32 \pm 0.88^{\mathrm{b}}$ & $16.77 \pm 0.52^{\mathrm{b}}$ \\
RS-treated + 0.1\% RS & $50.06 \pm 2.21^{\mathrm{b}}$ & $40.09 \pm 2.26^{\mathrm{c}}$ \\
RS-treated + 0.2\% RS & $109.46 \pm 8.67^{\mathrm{c}}$ & $87.09 \pm 2.53^{\mathrm{d}}$ \\
\hline
\end{tabular}

both SOM and RS) was the same across rice-planted and unplanted treatments. However, even if there was an effect of plants on $\delta^{13} \mathrm{C}_{\mathrm{CH}_{4}-\mathrm{SOR}}$, such an effect would not result in a large error of $f_{\text {ROC }}$ determined in Eqs. (2) or (3), since compared to the possible error in $\delta^{13} \mathrm{C}_{\mathrm{CH}_{4}-\mathrm{SOR}}$, the difference between $\delta^{13} \mathrm{C}_{\mathrm{CH}_{4}-\mathrm{SOR}}$ and $\delta^{13} \mathrm{C}_{\mathrm{CH}_{4}-\mathrm{ROC}}$ and between

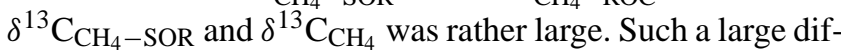
ference was created by the application of ${ }^{13} \mathrm{C}$-labeled rice straw (Yuan et al., 2012). Therefore, our assumptions in mass balance calculation should be rather robust, and thus calculated values of $f_{\mathrm{ROC}}$ and enhanced $\mathrm{CH}_{4}$ production rates from ROC after RS application should be valid.

Furthermore, for assessing the enhanced $\mathrm{CH}_{4}$ production rates from ROC, it is mainly the comparison of treatment with and without rice straw rather than with and without plants that is important (Table 1). The enhancement obtained from such comparison was consistent with the calculation from the total $\mathrm{CH}_{4}$ production rates $\left(p_{\mathrm{CH}_{4}}\right)$ and $f_{\mathrm{ROC}}$ (Fig. 2a).

\subsection{Positive feedback of $\mathrm{RS}$ addition on $\mathrm{CH}_{4}$ production from both SOM and ROC}

Our results quantified the positive feedback of RS addition on $\mathrm{CH}_{4}$ production from both SOM and ROC during the rice growth season. Stimulation of $\mathrm{CH}_{4}$ production by RS has commonly been observed as straw serves as a relatively labile organic substrate that is readily degraded to $\mathrm{CH}_{4}$ (Chidthaisong and Watanabe, 1997; Kimura et al., 2004; Sass et al., 1991; Schütz et al., 1989; Denier van der Gon and Neue, 1995; Yagi and Minami, 1990). It is known that at the beginning of flooding of rice fields, electrons derived from organic matter degradation are mainly used for the creation of reduced soil conditions (e.g., reduction of $\mathrm{O}_{2}, \mathrm{NO}_{3}^{-}$, $\mathrm{Fe}(\mathrm{III})$ and $\mathrm{SO}_{4}^{2-}$ ), while only the residual electrons can be 
used for $\mathrm{CH}_{4}$ production (Tokida et al., 2010; Yao and Con$\mathrm{rad}, 2000$ ). Addition of RS would increase the supply of electrons and thus allow a larger portion of the electrons (both from RS and SOM) being used for $\mathrm{CH}_{4}$ production. Such a mechanism has been already incorporated into process-based models of $\mathrm{CH}_{4}$ emission (Fumoto et al., 2008). However, such a mechanism could only explain the enhancement of $\mathrm{RS}$ on SOM-derived and ROC-derived $\mathrm{CH}_{4}$ production immediately after flooding of rice soil, since inorganic electron acceptors (e.g., $\mathrm{O}_{2}, \mathrm{NO}_{3}^{-}, \mathrm{Fe}(\mathrm{III})$ and $\mathrm{SO}_{4}^{2-}$ ) present in the soil are usually completely reduced after a few days or weeks (Yao and Conrad, 1999; Yao et al., 1999). This was also the case in our experiments (data not shown). However, the stimulation of $\mathrm{CH}_{4}$ production from ROC and SOM by RS was observed after 40 days of flooding of Vercelli soil when methanogenic conditions had well been established (Fig. 2a).

Methanogenic Vercelli soil slurry was used as a model system to study the priming effect (PE) of RS on anaerobic SOM decomposition production of $\mathrm{CH}_{4}$ and $\mathrm{CO}_{2}$ (TIC). It should be noted that organic matter is eventually degraded to equal amounts of $\mathrm{CH}_{4}$ and $\mathrm{CO}_{2}$ (e.g., cellulose):

$\mathrm{C}_{6} \mathrm{H}_{12} \mathrm{O}_{6} \rightarrow 3 \mathrm{CH}_{4}+3 \mathrm{CO}_{2}$.

However, $\mathrm{CH}_{4}$ is only produced from acetate and from $\mathrm{H}_{2}+$ $\mathrm{CO}_{2}$ so that part of the primarily produced $\mathrm{CO}_{2}$ is later reduced to $\mathrm{CH}_{4}$ :

$$
\mathrm{C}_{6} \mathrm{H}_{12} \mathrm{O}_{6}+2 \mathrm{H}_{2} \mathrm{O} \rightarrow 2 \mathrm{CH}_{3} \mathrm{COOH}+2 \mathrm{CO}_{2}+4 \mathrm{H}_{2},
$$

$2 \mathrm{CH}_{3} \mathrm{COOH} \rightarrow 2 \mathrm{CH}_{4}+2 \mathrm{CO}_{2}$,

$4 \mathrm{H}_{2}+\mathrm{CO}_{2} \rightarrow \mathrm{CH}_{4}+2 \mathrm{H}_{2} \mathrm{O}$.

While process (17) is achieved by hydrolytic and fermenting Bacteria, processes (18) and (19) are achieved by hydrogenotrophic and aceticlastic methanogens, respectively. As a result, $\mathrm{CO}_{2}$ is not only produced but also consumed during methanogenic degradation of organic matter. Therefore, priming effects in anoxic rice field soils may be different from those in oxic upland soils in which $\mathrm{CO}_{2}$ is only produced and is the sole product (Cheng, 2009; Kuzyakov, 2010). Conventionally, "priming effect" (PE) is defined as the enhancement of SOM degradation by labile organic substrates, which in upland soil is equivalent to $\mathrm{CO}_{2}$ production from SOM. However, in methanogenic rice field soil, production of both $\mathrm{CH}_{4}$ plus $\mathrm{CO}_{2}$ is equivalent to degradation of SOM. In our study we therefore differentiate between enhancement of $\mathrm{CH}_{4}$ production, $\mathrm{CO}_{2}$ production and $\mathrm{SOM}$ degradation (priming effect).

The following observations are noteworthy: (1) enhancement of $\mathrm{CH}_{4}$ production was observed after a certain period of anoxic degradation of RS (Figs. 3c and 4b), while $\mathrm{PE}$ of $\mathrm{CH}_{4}$ plus $\mathrm{CO}_{2}$ production was not observed (Fig. $4 \mathrm{~d}$ ). (2) Enhancement of $\mathrm{CH}_{4}$ production was mainly from hydrogenotrophic methanogenesis (Fig. 4c). (3) Degradation of
RS resulted in an increased abundance of methanogens, but not of Bacteria (Fig. 2b). (4) Previous degradation of RS resulted in enhancement of RS degradation at later treatment as seen in enhanced production of both $\mathrm{CH}_{4}$ and $\mathrm{CO}_{2}$ (Table 2). These results are most parsimoniously interpreted as follows: anoxic degradation of rice straw in Vercelli rice field soil was not limited by the abundance of Bacteria but by the abundance of methanogenic Archaea, explaining why preincubation of soil with RS increased the number of methanogens and the rates of TIC and $\mathrm{CH}_{4}$ production from new RS (Fig. 4b, Table 2) and also ROC (Fig. 2a), since both RS and ROC are rice-plant-derived labile carbon. Besides, preincubation of soil with RS resulted in the simultaneous enhancement of $\mathrm{CH}_{4}$ production from SOM (Figs. $3 c$ and $4 b$ ), which was mainly caused by enhancement of hydrogenotrophic $\mathrm{CO}_{2}$ reduction (Fig. 4c), so a $\mathrm{PE}$ of $\mathrm{CH}_{4}$ plus $\mathrm{CO}_{2}$ production (i.e., SOM decomposition) was not observed (Fig. 4d).

Previous studies have shown that the fermenting microorganisms that colonize RS and cause the primary hydrolysis and fermentation of the straw polysaccharides release fermentation products into the soil environments, where they are further degraded to $\mathrm{CH}_{4}$ and $\mathrm{CO}_{2}$ (Glissmann et al., 2001). Here we have shown that methanogenic reduction of SOM-derived $\mathrm{CO}_{2}$ is apparently also enhanced by fermentation products of RS degradation, presumably by $\mathrm{H}_{2}$. It has previously been observed that increased abundance of methanogens is paralleled by increased $\mathrm{CH}_{4}$ production (Liu et al., 2012). More specifically, it has been shown that RS treatment results in an increase of total $\mathrm{CH}_{4}$ production and in the abundance of methanogenic Archaea but not of Bacteria, and that the increase is mostly due to Methanosarcina species that are both potentially hydrogenotrophic and aceticlastic methanogens (Conrad and Klose, 2006; Conrad et al., 2012a). Here we have shown that this increase in methanogenic abundance further stimulated additional $\mathrm{CH}_{4}$ production from SOM.

In summary, our study demonstrated that RS is not only an additional substrate for $\mathrm{CH}_{4}$ production and enhances the creation of a reduced soil environment, but also causes a positive feedback on the $\mathrm{CH}_{4}$ production from both SOM and ROC, so the overall production of $\mathrm{CH}_{4}$ is larger than expected from the methanogenic degradation of RS alone. As $\mathrm{CH}_{4}$ emission increases with $\mathrm{CH}_{4}$ production (Fig. 1), the widespread application of RS will produce a non-linear response of $\mathrm{CH}_{4}$ emission to straw application, which will be important for process-oriented models of $\mathrm{CH}_{4}$ emission (Fumoto et al., 2008) and the assessment of future climate change due to $\mathrm{CH}_{4}$ (Montzka et al., 2011). 
Acknowledgements. We thank P. Claus and M. Klose for excellent technical assistance and two anonymous reviewers for helpful comments. The study is part of the ICON project funded by the German Research Foundation and the SYNMIKRO program funded by the Ministry of Hesse.

The service charges for this open access publication have been covered by the Max Planck Society.

Edited by: K. Küsel

\section{References}

Angel, R., Matthies, D., and Conrad, R.: Activation of methanogenesis in arid biological soil crusts despite the presence of oxygen, PLoS ONE, 6, e20453, doi:10.1371/journal.pone.0020453, 2011.

Bodelier, P. L. E., Hahn, A. P., Arth, I. R., and Frenzel, P.: Effects of ammonium-based fertilisation on microbial processes involved in methane emission from soils planted with rice, Biogeochemistry, 51, 225-257, 2000.

Cheng, W. X.: Rhizosphere priming effect: Its functional relationships with microbial turnover, evapotranspiration, and C-N budgets, Soil Biol. Biochem., 41, 1795-1801, doi:10.1016/j.soilbio.2008.04.018, 2009.

Chidthaisong, A. and Watanabe, I.: Methane formation and emission from flooded rice soil incorporated with ${ }^{13} \mathrm{C}$-labeled rice straw, Soil Biol. Biochem., 29, 1173-1181, 1997.

Conrad, R. and Klose, M.: Dynamics of the methanogenic archaeal community in anoxic rice soil upon addition of straw, Eur. J. Soil Sci., 57, 476-484, doi:10.1111/j.1365-2389.2006.00791.x, 2006.

Conrad, R., Klose, M., Lu, Y., and Chidthaisong, A.: Methanogenic pathway and archaeal communities in three different anoxic soils amended with rice straw and maize straw, Frontiers Microbiol., 3, 4, doi:10.3389/fmicb.2012.00004, 2012a.

Conrad, R., Klose, M., Yuan, Q., Lu, Y., and Chidthaisong, A.: Stable carbon isotope fractionation, carbon flux partitioning and priming effects in anoxic soils during methanogenic degradation of straw and soil organic matter, Soil Biol. Biochem., 49, 193199, doi:10.1016/j.soilbio.2012.02.030, 2012b.

Denier van der Gon, H. A. C. and Neue, H. U.: Influence of organic matter incorporation on the methane emission from a wetland rice field, Global Biogeochem. Cy., 9, 11-22, doi:10.1029/94gb03197, 1995.

De Troyer, I., Amery, F., Van Moorleghem, C., Smolders, E., and Merckx, R.: Tracing the source and fate of dissolved organic matter in soil after incorporation of a (13)C labelled residue: A batch incubation study, Soil Biol. Biochem., 43, 513-519, doi:10.1016/j.soilbio.2010.11.016, 2011.

Fumoto, T., Kobayashi, K., Li, C., Yagi, K., and Hasegawa, T.: Revising a process-based biogeochemistry model (DNDC) to simulate methane emission from rice paddy fields under various residue management and fertilizer regimes, Glob. Change Biol., 14, 382-402, doi:10.1111/j.1365-2486.2007.01475.x, 2008.

Glissmann, K., Weber, S., and Conrad, R.: Localization of processes involved in methanogenic degradation of rice straw in anoxic paddy soil, Environ. Microbiol., 3, 502-511, 2001.

Guenet, B., Juarez, S., Bardoux, G., Abbadie, L., and Chenu, C.: Evidence that stable $\mathrm{C}$ is as vulnerable to priming effect as is more labile $\mathrm{C}$ in soil, Soil Biol. Biochem., 52, 43-48, doi:10.1016/j.soilbio.2012.04.001, 2012.

Holzapfel-Pschorn, A. and Seiler, W.: Methane emission during a cultivation period from an Italian rice paddy, J. Geophys. Res., 91, 11803-11814, doi:10.1029/JD091iD11p11803, 1986.

Janssen, P. H. and Frenzel, P.: Inhibition of methanogenesis by methyl fluoride: studies of pure and defined mixed cultures of anaerobic bacteria and archaea, Appl. Environ. Microb., 63, 4552-4557, 1997.

Kimura, M., Murase, J., and Lu, Y. H.: Carbon cycling in rice field ecosystems in the context of input, decomposition and translocation of organic materials and the fates of their end products $\left(\mathrm{CO}_{2}\right.$ and $\left.\mathrm{CH}_{4}\right)$, Soil Biol. Biochem., 36, 1399-1416, doi:10.1016/j.soilbio.2004.03.006, 2004.

Krüger, M., Frenzel, P., and Conrad, R.: Microbial processes influencing methane emission from rice fields, Glob. Change Biol., 7, 49-63, 2001.

Kuzyakov, Y. and Bol, R.: Sources and mechanisms of priming effect induced in two grassland soils amended with slurry and sugar, Soil Biol. Biochem., 38, 747-758, doi:10.1016/j.soilbio.2005.06.025, 2006.

Kuzyakov, Y.: Priming effects: Interactions between living and dead organic matter, Soil Biol. Biochem., 42, 1363-1371, doi:10.1016/j.soilbio.2010.04.003, 2010.

Lelieveld, J., Crutzen, P. J., and Dentener, F. J.: Changing concentration, lifetime and climate forcing of atmospheric methane, Tellus B, 50, 128-150, 1998.

Li, C., Mosier, A., Wassmann, R., Cai, Z., Zheng, X., Huang, Y., Tsuruta, H., Boonjawat, J., and Lantin, R.: Modeling greenhouse gas emissions from rice-based production systems: Sensitivity and upscaling, Global Biogeochem. Cy., 18, GB1043, doi:10.1029/2003gb002045, 2004.

Liu, G. C., Tokida, T., Matsunami, T., Nakamura, H., Okada, M., Sameshima, R., Hasegawa, T., and Sugiyama, S.: Microbial community composition controls the effects of climate change on methane emission from rice paddies, Env. Microbiol. Rep., 4, 648-654, doi:10.1111/j.1758-2229.2012.00391.x, 2012.

Lu, Y., Wassmann, R., Neue, H. U., Huang, C., and Bueno, C. S.: Methanogenic responses to exogenous substrates in anaerobic rice soils, Soil Biol. Biochem., 32, 1683-1690, 2000.

Lueders, T. and Friedrich, M.: Archaeal population dynamics during sequential reduction processes in rice field soil, Appl. Environ. Microb., 66, 2732-2742, 2000.

Montzka, S. A., Dlugokencky, E. J., and Butler, J. H.: Non$\mathrm{CO}_{2}$ greenhouse gases and climate change, Nature, 476, 43-50, doi:10.1038/Nature10322, 2011.

Penning, H. and Conrad, R.: Carbon isotope effects associated with mixed-acid fermentation of saccharides by Clostridium papyrosolvens, Geochim. Cosmochim. Ac., 70, 2283-2297, doi:10.1016/j.gca.2006.01.017, 2006.

Penning, H. and Conrad, R.: Quantification of carbon flow from stable isotope fractionation in rice field soils with different organic matter content, Org. Geochem., 38, 2058-2069, doi:10.1016/j.orggeochem.2007.08.004, 2007.

Roy, R., Kluber, H. D., and Conrad, R.: Early initiation of methane production in anoxic rice soil despite the presence of oxidants, Fems. Microbiol. Ecol., 24, 311-320, 1997.

Sass, R. L., Fisher, F. M., Harcombe, P. A., and Turner, F. T.: Mitigation of methane emissions from rice fields: Possible adverse 
effects of incorporated rice straw, Global Biogeochem. Cy., 5, 275-287, doi:10.1029/91gb01304, 1991.

Schütz, H., Holzapfel-Pschorn, A., Conrad, R., Rennenberg, H., and Seiler, W.: A 3 year continuous record on the influence of daytime, season, and fertilizer treatment on methane emission rates from an Italian rice paddy, J. Geophys. Res., 94, 16405-16416, doi:10.1029/JD094iD13p16405, 1989.

Stubner, S.: Enumeration of 16S rDNA of Desulfotomaculum lineage 1 in rice field soil by real-time PCR with SybrGreen (TM) detection, J. Microbiol. Meth., 50, 155-164, 2002.

Stumm, W. and Morgan, J. J.: Aquatic chemistry. An introduction emphasizing chemical equilibria in natural waters, Wiley, 1981.

Tokida, T., Fumoto, T., Cheng, W., Matsunami, T., Adachi, M., Katayanagi, N., Matsushima, M., Okawara, Y., Nakamura, H., Okada, M., Sameshima, R., and Hasegawa, T.: Effects of freeair $\mathrm{CO}_{2}$ enrichment (FACE) and soil warming on $\mathrm{CH}_{4}$ emission from a rice paddy field: impact assessment and stoichiometric evaluation, Biogeosciences, 7, 2639-2653, doi:10.5194/bg-72639-2010, 2010.

Tokida, T., Adachi, M., Cheng, W. G., Nakajima, Y., Fumoto, T., Matsushima, M., Nakamura, H., Okada, M., Sameshima, R., and Hasegawa, T.: Methane and soil $\mathrm{CO}_{2}$ production from currentseason photosynthates in a rice paddy exposed to elevated $\mathrm{CO}_{2}$ concentration and soil temperature, Glob. Change Biol., 17, 3327-3337, doi:10.1111/j.1365-2486.2011.02475.x, 2011.

Watanabe, A., Yoshida, M., and Kimura, M.: Contribution of rice straw carbon to $\mathrm{CH}_{4}$ emission from rice paddies using ${ }^{13}$ C-enriched rice straw, J. Geophys. Res., 103, 8237-8242, doi:10.1029/97jd03460, 1998.
Watanabe, A., Takeda, T., and Kimura, M.: Evaluation of origins of $\mathrm{CH}_{4}$ carbon emitted from rice paddies, J. Geophys. Res., 104, 23623-23629, doi:10.1029/1999jd900467, 1999.

Yagi, K. and Minami, K.: Effect of organic matter application on methane emission from some Japanese paddy fields, Soil Sci. Plant Nutr., 36, 599-610, doi:10.1080/00380768.1990.10416797, 1990.

Yao, H. and Conrad, R.: Thermodynamics of methane production in different rice paddy soils from China, the Philippines and Italy, Soil Biol. Biochem., 31, 463-473, 1999.

Yao, H., Conrad, R., Wassmann, R., and Neue, H. U.: Effect of soil characteristics on sequential reduction and methane production in sixteen rice paddy soils from China, the Philippines, and Italy, Biogeochemistry, 47, 269-295, 1999.

Yao, H. and Conrad, R.: Effect of temperature on reduction of iron and production of carbon dioxide and methane in anoxic wetland rice soils, Biol. Fert. Soils, 32, 135-141, 2000.

Yuan, Q., Pump, J., and Conrad, R.: Partitioning of $\mathrm{CH}_{4}$ and $\mathrm{CO}_{2}$ production originating from rice straw, soil and root organic carbon in rice microcosms, PLoS ONE, 7, e49073, doi:10.1371/journal.pone.0049073, 2012.

Zhu, B. and Cheng, W. X.: Rhizosphere priming effect increases the temperature sensitivity of soil organic matter decomposition, Glob. Change Biol., 17, 2172-2183, doi:10.1111/j.13652486.2010.02354.x, 2011. 